\title{
CERIA DOPED ALUMINA BY SPARK PLASMA SINTERING FOR OPTICAL
}

\section{APPLICATIONS}

\author{
Isabel Alvarez-Clemares ${ }^{a}$, Gustavo Mata-Osoro $^{b}$, Adolfo Fernández $^{c}$, \\ Sonia Lopez-Esteban ${ }^{a}$, Carlos Pecharroman $^{b}$, Ramon Torrecillas $^{a}$ and Jose S. Moya $^{b}$.
}

\author{
${ }^{a}$ Centro de Investigación en Nanomateriales y Nanotecnología [Consejo Superior de \\ Investigaciones Científicas (CSIC)-Universidad de Oviedo (UO)-Principado de \\ Asturias (PA)]. \\ Parque Tecnológico de Asturias, 33428 Llanera (Spain) \\ ${ }^{b}$ Instituto de Ciencia de Materiales de Madrid (ICMM), Consejo Superior de \\ Investigaciones Científicas (CSIC), Cantoblanco, 28049 Madrid (Spain) \\ ${ }^{c}$ Fundación ITMA, Parque Tecnológico de Asturias, 33428 Llanera (Spain)
}

\begin{abstract}
$\mathrm{Al}_{2} \mathrm{O}_{3}-\mathrm{CeO}_{2}$ ceramics were found to be transparent in the IR range and high-traslucent in the visible range. The surface of nanometric $\alpha$-alumina particles was modified by deposition-precipitation of small fractions of ceria nanoparticles. The powders were sintered using Spark Plasma Sintering. Values of Real In-line Transmittance up to $70 \%$ in the IR-Vis range have been measured. Transparency enhancement has been attributed to Cerium oxide nanoparticles located at the grain boundaries and triple points. These particles are hindering alumina grain growth during SPS at a temperature as high as $1430^{\circ} \mathrm{C}$. This effect is found to be effective under SPS low vacuum conditions and short dwell times. The optimum ceria content was found to be 0.7 wt.\%. Diffusion in $\mathrm{Al}_{2} \mathrm{O}_{3}$ -
\end{abstract}


$\mathrm{CeO}_{2}$ as a function of the atmosphere has been studied in diffusion couples. The results obtained by the proposed route are discussed considering the data reported in the literature for SPS $_{\text {ed }}$ transparent alumina.

Keywords: Optical properties, $\mathrm{Al} 2 \mathrm{O} 3, \mathrm{CeO} 2$, sintering. 


\section{Introduction}

The combination of high transparency and excellent mechanical properties such as hardness or chemical stability, makes Polycrystalline Transparent Alumina (PTA) an interesting option in industrial and military applications such as armour parts, discharge lamps, airborne infrared sensors and laser [1]. However, obtaining large or complex shaped PTAs samples is still a challenge. The achievement of transparency in this material needs the accomplishment of mainly two requirements. Firstly, the residual porosity in the material has to be lower than 0.05 vol.\% [2]. Secondly, the grain size has to be as small as possible in order to minimize the effect of the birrefringent character of alumina. In this context, the key factor to achieve these goals seems to be the control of the grain growth in order to decrease the flaw size $(<100 \mathrm{~nm})$ and, therefore, the volume of porosity.

The effect of the addition of small percentages of dopants such as $\mathrm{Mg}, \mathrm{Ti}, \mathrm{Ca}[3-5], \mathrm{Zr}$, $\mathrm{Y}$ or Ln in the optical properties of alumina has been widely studied in further investigations. High transparency has been achieved using both sinter-HIP [6] and SPS[7] with $\mathrm{MgO}$ dopants. Despite the fact that these compounds modify the grain growth rate in alumina, it is not evident to achieve transparency due to the anisotropic character of the alumina grains. In this regard, alumina/ceria is a promising system due to its ability to change its oxidation state with oxygen partial pressure [8], as well as the grain growth inhibition [6], which permits to use the sintering atmosphere to control the grain growth instead of the restrictive heating rates in SPS. In the present work, the influence of $\mathrm{CeO}_{\mathrm{x}}$ doping on the transparency of SPSed alumina compacts is investigated $\left(\mathrm{CeO}_{\mathrm{x}}\right.$ is a mixture of $\mathrm{Ce}_{2} \mathrm{O}_{3}$ and $\mathrm{CeO}_{2}$ (according to XPS analysis approximately in a proportion of 50\%), as reported in our previous work [9], where the 
oxidation state of cerium has been determined for SPSed samples in vaccum by means of XPS analyses.

\section{Materials and methods}

Pure a-alumina (Taimei TM-DAR, average particle size: $170 \mathrm{~nm}$, Taimicrons, Japan) and a ceria precursor (Cerium (III) acetate hydrated, Sigma Aldrich) have been used to prepare alumina/ceria nanopowders. Powders with $\mathrm{CeO}_{2}$ contents of $0.3,0.5,0.7$ and 1 wt.\% have been prepared, following the wet processing route described by the authors elsewhere [9]. Pure alumina has been sintered under the same conditions for comparison purposes. The alumina/ceria powders have been uniaxially pressed at $15 \mathrm{MPa}$ and subsequently Spark Plasma Sintered in vacuum $\left(10^{-2} \mathrm{mbar}\right)$ at $1430^{\circ} \mathrm{C}$. The heating rate was $50^{\circ} \mathrm{C} \cdot \mathrm{min}^{-1}$; a pressure of $80 \mathrm{MPa}$ was applied after reaching the temperature of $600^{\circ} \mathrm{C}$, until the end of the process. The dwell time at the maximum temperature was 2 min. A summary of the different samples studied is presented in Table $\mathbf{1 .}$

The reactivity of the $\mathrm{Al}_{2} \mathrm{O}_{3}-\mathrm{CeO}_{2}$ system in pressureless sintering as a function of the atmosphere has been determined by means of diffusion couples. $\mathrm{Al}_{2} \mathrm{O}_{3}$ and $\mathrm{CeO}_{2}$ laminates have been pressed at $200 \mathrm{MPa}$ and sintered at $1600^{\circ} \mathrm{C}$ in air during $2 \mathrm{~h}$. Once sintered, the surface of the samples was polished down to $1 \mu \mathrm{m}$. The polished surfaces

of alumina and ceria laminates $(5 \times 2 \times 2 \mathrm{~mm})$ were kept in contact under the weight of a block of alumina $(20 \mathrm{~g})$. The diffusion couples were heated at $1500^{\circ} \mathrm{C}$ for $12 \mathrm{~h}$ in either argon or air. Once treated, the cross section of the samples were polished down to 1 micron and the diffusion behaviour of the different species was observed by Scanning Electron Microscopy (SEM, Hitachi TM3000) provided with EDX analysis (Bruker, Quantax 70). 
For the measurement of the optical properties, the surfaces were polished down to $1 \mu \mathrm{m}$ using diamond paste. The real in-line transmittance (RIT) spectra of the sintered samples were determined in the range 2.5-5 $\mu \mathrm{m}$ with a Nicolet 20 SXC FTIR spectrophotometer; for the 0.9-2.5 $\mu \mathrm{m}$ range, a Bruker IFS 66V FTIR spectrophotometer was used; finally, in the visible range, measurements were carried out with a JASCO V-660 spectrophotometer.

The microstructure of the polished samples was observed by Field-Emission-Scanning Electron Microscopy (FE-SEM, Zeiss Ultraplus) and SEM. The samples were previously thermally etched in vacuum to activate their surfaces. For that purpose, the selected temperature was $0.7 \cdot T_{s}$, where $T_{s}$ represents the sintering temperature of the sample. The etching time was five minutes. Grain size of alumina samples was calculated by an intercept method [10]. The crystalline phases formed in the different materials were analysed by X-ray Diffraction (Bruker D8).

\section{Theory/calculation}

For the explanation of the light scattering behaviour in the near-IR (NIR) and visible (VIS) range, a light scattering model under the approximation for polycrystalline alumina has been introduced. The model states that transmittance of well-polished dense alumina has two main scattering mechanisms: pore scattering (given by a Rayleigh approximation) and grain scattering (model by a Rayleigh-Gans-Debye expression). The first one is the classical $(a / \lambda)^{4}$ scattering law (being $a$ the pore radius and $\lambda$ the incident wavelength) while the second one follows a $(a / \lambda)^{2}$ law[11]. In a recent paper [12], it has been shown that, not only on the maximum grain size is relevant for light scattering in anisotropic ceramics, but also the preferential orientation 
of their c-axis, or texture must be taken into account. The effect of texture in transparency experimentally measured on dense alumina samples with different grain size has shown very good agreement with the results of x-ray Rietveld refinements. The analytical expression for the scattering efficiency factor is

$$
Q_{R G D}(x, \xi)=2 x^{2} \frac{\Delta n^{2}}{n_{a v}^{2}} \alpha(\xi)
$$

where $\Delta n$ is the difference between the refraction index in the different axis (equals to 0.008 for $\alpha$-alumina) and $d$ is the thickness of the sample. Using these variables, a straight line is obtained for the Rayleigh-Gans-Debye approximation, its slope being proportional to the maximum grain size $a_{g}$ and textural parameter $\alpha(\xi)$.

The total scattering efficiency factor is the sum of the scattering contribution of grains plus pores[11]:

$$
Q=Q_{R}+Q_{R G D}=\frac{8}{3}\left|\frac{\Delta n_{a v}^{2}-1}{\Delta n_{a v}^{2}+2}\right|^{2}\left(\frac{2 \pi a_{d}}{\lambda}\right)^{4}+2\left(\frac{2 \pi a_{g}}{\lambda}\right)^{2} \frac{\Delta n^{2}}{n_{a v}^{2}} \alpha(\xi)
$$

Where $a_{d}$ is the deffect size and $\Delta n_{\mathrm{av}}$ the relative refractive index contrast in respect to the ceramic matrix. The relationship of the scattering efficiency factor with absorbance coefficient $\kappa$ is given by:

$$
\begin{aligned}
& \kappa=\pi a^{2} Q N \\
& \kappa=\frac{3}{4}\left(f_{p} \frac{Q_{R}}{a_{p}}+\frac{Q_{R G D}}{a_{g}}\right)
\end{aligned}
$$

Where $N$ is the volume density of defects and $f_{p}$ is the volume concentration of pore/inclusions. The total transmittance is therefore given by the light transmitted through a transparent samples (only affected by reflectance losses) times the factor which takes into account the scattering absorption through a thickness $d$. 
$T=\left[1-2\left(\frac{n_{a v}-1}{n_{a v}+1}\right)^{2}\right] e^{-\kappa d}$

Expression (4) can be rewritten in the following mode.

$-\log ($ R.I.T. $)=-\log \left(T_{0}\right)+\frac{6 \pi^{2}\left\langle a_{g}\right\rangle}{\lambda^{2}} \Delta n^{2} \alpha(\xi) d+\frac{32 f_{p} \pi^{4}\left\langle a_{d}^{3}\right\rangle}{\lambda^{4}}\left|\frac{\Delta n_{a v}^{2}-1}{\Delta n_{a v}^{2}+2}\right|^{2} d$

$$
A=A_{0}+\left(\frac{B_{d}}{\lambda^{2}}+\frac{B_{g}}{\lambda^{4}}\right) d
$$

$$
\begin{aligned}
& A_{0}=-\log \left(T_{0}\right) \\
& B_{d}=\frac{32 f_{p} \pi^{4}\left\langle a_{d}^{3}\right\rangle}{\lambda^{4}}\left|\frac{\Delta n_{a v}^{2}-1}{\Delta n_{a v}^{2}+2}\right|^{2} \\
& B_{g}=\frac{6 \pi^{2}\left\langle a_{g}\right\rangle}{\lambda^{2}} \Delta n^{2} \alpha(\xi)
\end{aligned}
$$

In this particular system, the presence of a very small amount of $\mathrm{CeO}_{2}$ will also contribute to light scattering. In the case of transparent matrices with $\mathrm{CeO}_{2}$, the refractive index of $\mathrm{CeO}_{2}\left(n_{\mathrm{CeO} 2}=2.36\right)$ is very different from that of the alumina $(n=1.76)$ and assuming that $\mathrm{CeO}_{2}$ grain size, $a_{d}$, is much smaller than the maximum grain size $\left(a_{d}<<a_{\mathrm{g}}\right)$, Rayleigh scattering must be taken into account. It is also worth to remark that ceria/alumina contrast is very close to that of air/alumina, so that it is hard to distinguish the Rayleigh scattering from pores and from ceria grains.

Thus, in case of a representation of absorbance vs. $1 / \lambda^{2}$ it is very simple to determine in which spectral region the main scattering mechanism is the one due to grains (linear regime) and defects (quadratic regime). Therefore, this model offers an additional and simple tool for a complete bulk evaluation of the microstructure (grain size, texturing, porosity, etc.) of the sintered polycrystalline alumina samples. This bulk microstructural 
information is critical to fabricate transparent polycrystalline alumina compacts and cannot be obtained by conventional microstructural analysis (i.e. Transmission and Scanning Electron Microscopy, X-Ray Diffraction).

\section{Results}

\subsection{Diffusion activity.}

The diffusion activity of $\mathrm{Al}_{2} \mathrm{O}_{3}$ and $\mathrm{CeO}_{2}$ was studied by diffusion couples, an assembly of the two materials in such intimate contact that each one diffuses into the other. The cross section of the diffusion couples was studied in two atmosheres: argon (Figure 1a) and air (Figure 1b). In the case of argon atmosphere, the total fraction of $\mathrm{CeO}_{2}$ was reduced to $\mathrm{Ce}_{2} \mathrm{O}_{3}$. At the interface of both materials, the formation of two compounds can be detected. After the identification by XRD, it can be stated that these compounds correspond to $\mathrm{CeAl}_{11} \mathrm{O}_{18}$ and $\mathrm{CeAlO}_{3}$. According to the EDX analysis of the cross section of the couple (Figure 1c) there is interdiffusivity of ions $\mathrm{Al}$ and $\mathrm{Ce}$. As a result, the $\mathrm{Al}^{3+}$ rich compound is formed near the alumina face and the $\mathrm{Ce}^{3+}$ rich cerium aluminate is formed near the ceria face. These results are in perfect agreement with the $\mathrm{Al}_{2} \mathrm{O}_{3}-\mathrm{Ce}_{2} \mathrm{O}_{3}$ phase diagram proposed by Mizuno [13]. Moreover, the presence of $\mathrm{Ce}$ has been detected in the region of $\mathrm{Al}_{2} \mathrm{O}_{3}$ near the interface $\mathrm{Al}_{2} \mathrm{O}_{3}-\mathrm{CeAl}_{11} \mathrm{O}_{18}$, which suggests the possible existence of a solid solution only detected in the case of argon, and not reported before in literature.

when the diffusion couple is heat-treated in air (Figure 1b), no diffusion takes place and no intermediate compounds are formed, as the $\mathrm{Al}_{2} \mathrm{O}_{3}-\mathrm{CeO}_{2}$ diagram predicts [13]. According to these results, the formation of intermediate compounds can only be expected in either neutral or reducing atmospheres. 
According to previous investigations [9], the samples $\mathrm{SPS}_{\mathrm{ed}}$ in vacuum at $1430^{\circ} \mathrm{C}$ for two minutes present the same oxidation state as the starting powder. Only in SPS samples obtained under reducing atmospheres $\left(\mathrm{Ar} / \mathrm{H}_{2}\right)$ or long dwell times in vacuum, the $\mathrm{Ce}^{4+}$ is reduced to $\mathrm{Ce}^{3+}$.

\subsection{Microstructure of the SPSed materials}

The microstructures of the Spark Plasma Sintered samples as a function of the ceria content are shown in Figure 2. The nanoparticles can only be detected at higher magnifications, as shown in the micrographs of the fracture surfaces presented in

Figure 3. These $\mathrm{CeO}_{2}$ nanoparticles tend to concentrate at the grain boundaries and triple points, reducing the final porosity, as well as the size of the larger remaining pores in the final material in comparison with pure alumina (Figure 3a). According to these micrographs it can be generally stated that cerium oxide particles are in the nanometric scale and presented an average particle size of approximately $30 \pm 10 \mathrm{~nm}$ (Figure 3b). Aggregates of ceria larger than $100 \mathrm{~nm}$ can only be found in the sample with the highest $\mathrm{CeO}_{2}$ content (Figure 3c).

According to the grain size measurements (Table 1) it can be stated that $\mathrm{CeO}_{\mathrm{x}}$ nanoparticles act efficiently as grain growth inhibitors of alumina for samples with 0.3 $0.7 \mathrm{wt} \%$. of $\mathrm{CeO}_{2}$. In this range, the largest average-grain-size obtained was the one corresponding to the sample Ace-03 $(0.72 \pm 0.11 \mu \mathrm{m})$; the smallest average-grain-size was obtained for sample Ace-07 $(0.38 \pm 0.03 \mu \mathrm{m})$; in the case of the samples with $1 \mathrm{wt} . \%$ 
of $\mathrm{CeO}_{2}$, the grain growth inhibition was less efficient due to the presence $\mathrm{CeO}_{2}$ aggregates $(0.47 \pm 0.02 \mu \mathrm{m}$ average grain size $)$.

\subsection{Optical characterization.}

In order to compare the effect of the ceria content in the transmittance, samples sintered in SPS with 0, 0.3, 0.5, 0.7 and 1 wt.\% of ceria have been measured (Figure 4). The transmittance of the samples increases with the ceria content up to $1 \mathrm{wt}$. ceria, in which the transmittance drops drastically. Following the theoretical model, the $\log (\mathrm{T})$ vs. $1 / \lambda^{2}$ of the considered samples are plotted in Figure 5; for the low spectral range, the experimental data fit to a straight line. According to XRD data obtained on sintered samples (data not shown), no texturing was detected. In this regard, we assigned the texture angle $\alpha(\xi)=0.277$, which corresponds to random orientation $\left(\xi=45^{\circ}\right)$ [13]. The fit can be used to determine the average alumina grain size. As can be seen in Table 1, the value of the maximum grain size calculated for samples of $0.3,0.5$ and 0.7 wt. $\%$ ceria are in very good agreement with the experimental results (Table 1). In 0, 0.3 and 0.5 wt. $\%$ ceria samples, the slope of the line is very high and it saturates for higher values of $1 / \lambda^{2}$. This behaviour is typical of coarse grain aluminas and is due to an additional scattering mechanism called anomalous scattering [11- 12]. By the opposite, the linear behaviour corresponding to the $0.7 \mathrm{wt} . \%$ ceria sample in this representation indicates a negligible porosity and/or scattering by $\mathrm{CeO}_{2}$ nanoparticles, so that this concentration is able to control the alumina grain size without introducing significant Rayleigh scattering by the very small ceria nanoparticles neither by porosity. In the case of $1 \mathrm{wt} \%$ $\mathrm{CeO}_{2}$, it is not possible to apply this model. This fact could be explained considering the Mie equation [14], thus the scattering of ceria grains and aggregates (larger than 100 
nm) will introduce some additional complicated wavelength dependence to equation (6).

\section{Discussion}

According to the couple diffusion experiments performed in $\mathrm{Ar}$ atmosphere, $\mathrm{Ce}^{3+}$ is the only specie with the ability to form a solid solution and $\mathrm{CeAl}_{11} \mathrm{O}_{18}$ when the solubility limit is reached, as predicted by Mizuno [13] (Figure 6). As a result, the presence of a solid solution region in the $\mathrm{Al}_{2} \mathrm{O}_{3}-\mathrm{Ce}_{2} \mathrm{O}_{3}$ phase diagram is proposed in Figure 6. This solid solution region has not been reported in the literature. Further studies are needed to verify the current findings.

Despite the fact that Spark Plasma Sintering was performed in vacuum, no intermediate compounds where detected and only $\mathrm{CeO}_{\mathrm{x}}$ nanoparticles were found. As it has been pointed out in a previous work [9], XPS analysis of the ceria doped alumina materials sintered in vacuum reveal that the fraction of $\mathrm{Ce}^{4+}$ and $\mathrm{Ce}^{3+}$ remains the same as that of the starting powders. This supports the hypothesis that, due to the high heating rates and short dwell times applied during the process, the $\mathrm{Ce}^{4+}$ remains unreduced and the main fraction of $\mathrm{Ce}^{3+}$ remains in grain boundaries and not in solid solution, as predicted by the equilibrium diagram ( Figure 6), forming $\mathrm{CeO}_{\mathrm{x}}$ nanoparticles $\left(\mathrm{CeO}_{\mathrm{x}}\right.$ is a mixture of $\mathrm{Ce}_{2} \mathrm{O}_{3}$ and $\mathrm{CeO}_{2}$ (according to XPS analysis approximately in a proportion of 50\%), as reported in our previous work [9], where the oxidation state of cerium has been determined for SPSed samples in vaccum by means of XPS analyses. This information has been included in the corrected manuscript. This also suggests further work is needed to precise the Solid Solution extension. 
According to the microstructural analysis, these nanoparticles act as grain growth inhibitors of alumina, reducing its final grain size. Moreover, the nanoparticles tend to concentrate at the grain boundaries and triple points of alumina, closing the pores located at these positions (Figure 3a), enhancing the transparency of the material. In this regard, the optimum percentage of $\mathrm{CeO}_{2}$ was found to be $0.7 \mathrm{wt} \%$. The RIT obtained for this sample represents an improvement in comparison to the values obtained in other SPS studies $[15,16]$. Better transmittances have only been achieved in other studies with doped alumina freeze dried powders [7]. In this regard, significant improvement should be possible with a better dispersion of the nanoparticles and the elimination of any remaining porosity. In this particular sample (Figure 4), the level of transmittance reached comes closer to that of single crystals $[2,6,17,18]$ in the far infrared. Lower ceria contents lead to bigger average grain size, thus birefringence becomes more important, and higher percentages of $\mathrm{CeO}_{2}$ lead to second phase aggregation with relatively coarse sizes (> $100 \mathrm{~nm}$ ) and, as a consequence of the difference between the refractive index of alumina and ceria, the transparency of the material is reduced (Figure 4, Figure 5).

In summary, the advantages of the alumina-cerium oxide nanoparticles system are the following: i) we can avoid the reduction of $\mathrm{Ce}^{4+}$ to $\mathrm{Ce}^{3+}$ with the SPS atmosphere (by using low vacuum instead of hydrogen or $\mathrm{Ar}-\mathrm{H}_{2}$ ); ii) we can use conventional submicronic alumina powders (such as, for instance, Taimei) because the strong limitation of the maximum temperature for SPS (around $1200^{\circ} \mathrm{C},[2,15,19]$ ) to avoid alumina grain growth does not affect the process. iii) The presence of ceria nanoparticles located at the grain boundaries facilitates, during the SPS process, the filling of the triple points of alumina grains and, consequently, hinders the growth of the 
pores usually located at such triple points, reducing pore scattering. iv) The cerium oxide nanoparticles hinder the growth of alumina grains avoiding grain scattering.

\section{Conclusion}

Consequently, these ceria doped alumina open a new promising avenue to fabricate transparent alumina by SPS. In this particular system, by controlling the fraction of ceria as well as the SPS sintering atmosphere and dwell time [9], it can be possible to by-pass the intrinsic limitations to fabricate transparent alumina by SPS, such as the low temperature treatments to avoid grain growth $\left(\mathrm{T} \sim 1200^{\circ} \mathrm{C}\right)$, and the accepted need to produce alumina powders in the nanometer range [19-21].

\section{Acknowledgements}

This work was supported by the Spanish Ministry of Science and Innovation (MICINN) under the project MAT2009-14542-C02-02. Isabel Alvarez-Clemares wants to acknowledge the support received by Fundación para el Fomento en Asturias de la Investigación Científica aplicada y la Tecnologia (FICYT), under the program Severo Ochoa (BP07-050).Gustavo Mata-Osoro was supported by the Spanish Ministry of Education and Science under the project MAT2006-10249-C02-01. 


\section{References}

[1] Cheng JP, Agrawal D, Zhang YJ, Roy R. Microwave sintering of transparent alumina. Materials Letters 2002;56:587.

[2] Kim BN, Hiraga K, Morita K, Yoshida H, Miyazaki T, Kagawa Y. Microstructure and optical properties of transparent alumina. Acta Materialia 2009;57:1319.

[3] Hilli N, Goeuriot P. Sintering of monodoped and mixtures of monodoped alpha alumina powders. Symposium on Powder Science and Technology - Powders and Sintered Material. Albi, FRANCE: Elsevier Science Sa, 2007. p.129.

[4] Bernard-Granger G, Guizard C. Influence of $\mathrm{MgO}$ or $\mathrm{TiO} 2$ doping on the sintering path and on the optical properties of a submicronic alumina material. Scripta Materialia 2007;56:983.

[5] Bernard-Granger G, Guizard C, Addad A. Influence of Co-Doping on the Sintering Path and on the Optical Properties of a Submicronic Alumina Material. Journal of the American Ceramic Society 2008;91:1703.

[6] Krell A, Blank P, Ma HW, Hutzler T, van Bruggen MPB, Apetz R. Transparent sintered corundum with high hardness and strength. Journal of the American Ceramic Society $2003 ; 86: 12$.

[7] Stuer M, Zhao Z, Aschauer U, Bowen P. Transparent polycrystalline alumina using spark plasma sintering: Effect of Mg, Y and La doping. Journal of the European Ceramic Society;30:1335.

[8] Shyu JZ, Weber WH, Gandhi HS. Surface characterization of alumina supported ceria. Journal of physical chemistry 1988;92:4964. 
[9] Alvarez-Clemares I, Mata-Osoro G, Fernández A, Lopez-Esteban S, Pecharromán C, Palomares J, Torrecillas R, Moya JS. Transparent Alumina/Ceria Nanocomposites By Spark Plasma Sintering. Advanced Engineering Materials;12:1154.

[10] Mendelson MI. Average Grain Size in Polycrystalline Ceramics. Journal of the American Ceramic Society 1969;52:443.

[11] Hulst HCvd. Light scattering by small particles. Dover Courier Pblications, 1981.

[12] Pecharromán C, Mata-Osoro G, Díaz LA, Torrecillas R, Moya JS. On the transparency of nanostructured alumina: Rayleigh-Gans model for anisotropic spheres. Optics Express 2009;17:6899.

[13] M. Mizuno RB, J. P. Coutures, and M. Foex. Yogyo Kyokaishi 1975;83:90.

[14] Bohren CF and Huffman DR, editor Absorption and scattering of light by small particles.: Wiley, 1983.

[15] Kim BN, Hiraga K, Morita K, Yoshida H. Spark plasma sintering of transparent alumina. Scripta Materialia 2007;57:607.

[16] Zhan G-D, Kuntz J, Wan J, Garay J, Mukherjee AK. Alumina-based nanocomposites consolidated by spark plasma sintering. Scripta Materialia 2002;47:737.

[17] Apetz R, van Bruggen MPB. Transparent alumina: A light-scattering model. J. Am. Ceram. Soc. 2003;86:480.

[18] Krell A, Klimke J, Hutzler T. Advanced spinel and sub-[mu]m Al2O3 for transparent armour applications. Journal of the European Ceramic Society 2009;29:275. [19] Shen ZJ, Johnsson M, Zhao Z, Nygren M. Spark plasma sintering of alumina. J. Am. Ceram. Soc. 2002;85:1921. 
[20] Jiang D, Hulbert DM, Anselmi-Tamburini U, Ng T, Land D, Mukherjee AK. Optically transparent polycrystalline $\mathrm{A} 12 \mathrm{O} 3$ produced by spark plasma sintering. Journal of the American Ceramic Society 2008;91:151.

[21] Jiang D, Hulbert DM, Anselmi-Tamburini U, Ng T, Land D, Mukherjee AK. Spark plasma sintering and forming of transparent polycrystalline $\mathrm{Al}(2) \mathrm{O}(3)$ windows and domes - art. no. 654509. Window and Dome Technologies and Materials X 2007;6545:54509. 


\section{Figure and Table captions}

Table 1. Ceria content and grain sizes of the different SPSed samples.

Figure 1. Cross section micrographs of the diffusion couples $\mathrm{Al}_{2} \mathrm{O}_{3}-\mathrm{CeO}_{2}$. A) Treated in argon; b) treated in air; c) Detail and EDX analysis of the interface $\mathrm{Al}_{2} \mathrm{O}_{3}$ $\mathrm{CeAl}_{11} \mathrm{O}_{18}$ of the diffusion couple treated in argon.

Figure 2. FE-SEM micrographs of Spark Plasma Sintered ceria doped alumina samples (polished surfaces).

Figure 3. FE-SEM micrographs of the surface fracture of Spark Plasma sintered samples: a) $\mathrm{Al}_{2} \mathrm{O}_{3}$; b) alumina with 0.5 wt.\% of ceria and c) alumina with 1 wt.\% of ceria composite (c).

Figure 4. RIT transmittance of the Spark Plasma sintered ceria doped alumina (sample diameter: $0.80 \mathrm{~mm}$ ) as a function of the ceria content.

Figure 5. Fitting of the optical data of the SPSed ceria doped alumina to the theoretical model.

Figure 6. $\mathrm{Al}_{2} \mathrm{O}_{3}-\mathrm{Ce}_{2} \mathrm{O}_{3}$ phase diagram proposed by Mizuno et al [14]. A solid solution region has been proposed by the authors (dot line). 
Click here to download high resolution image

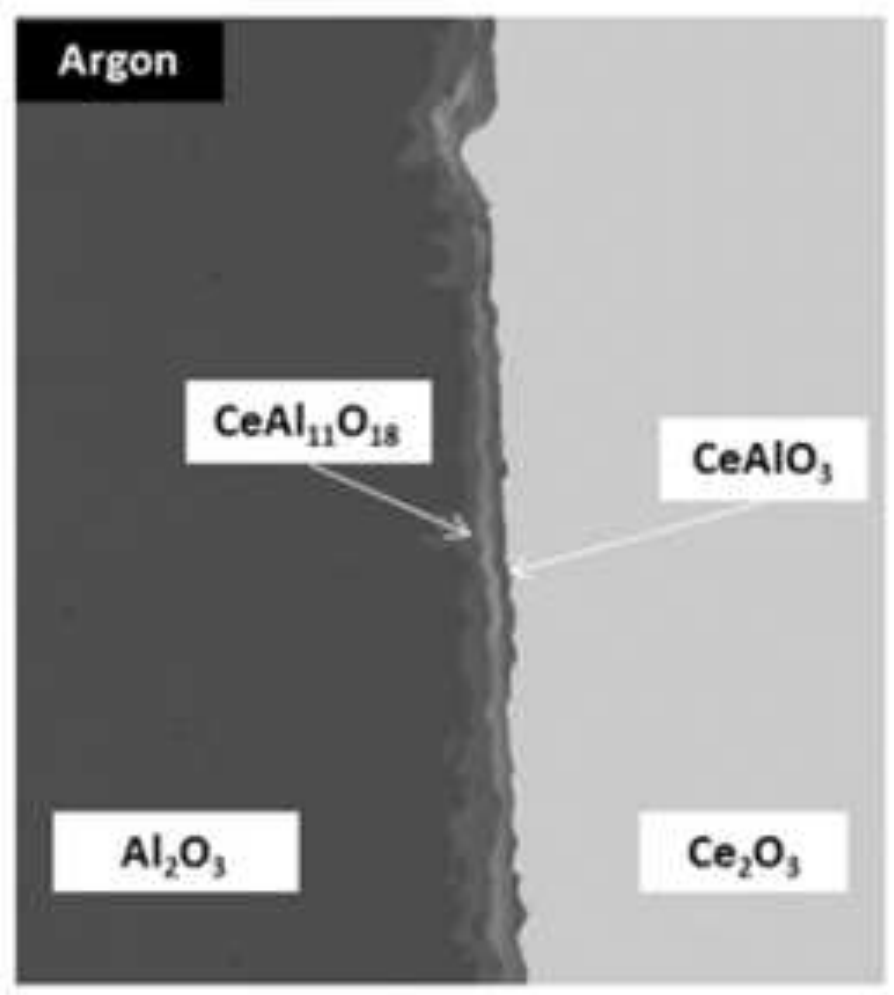

a)

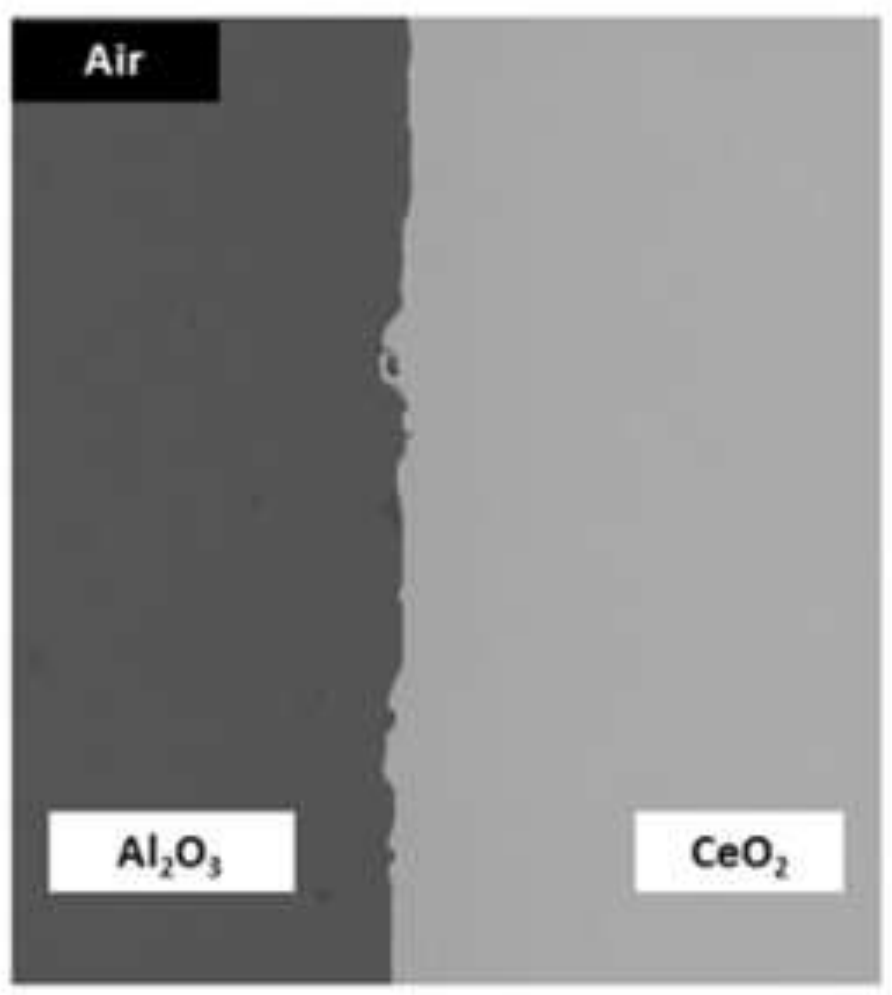

b)

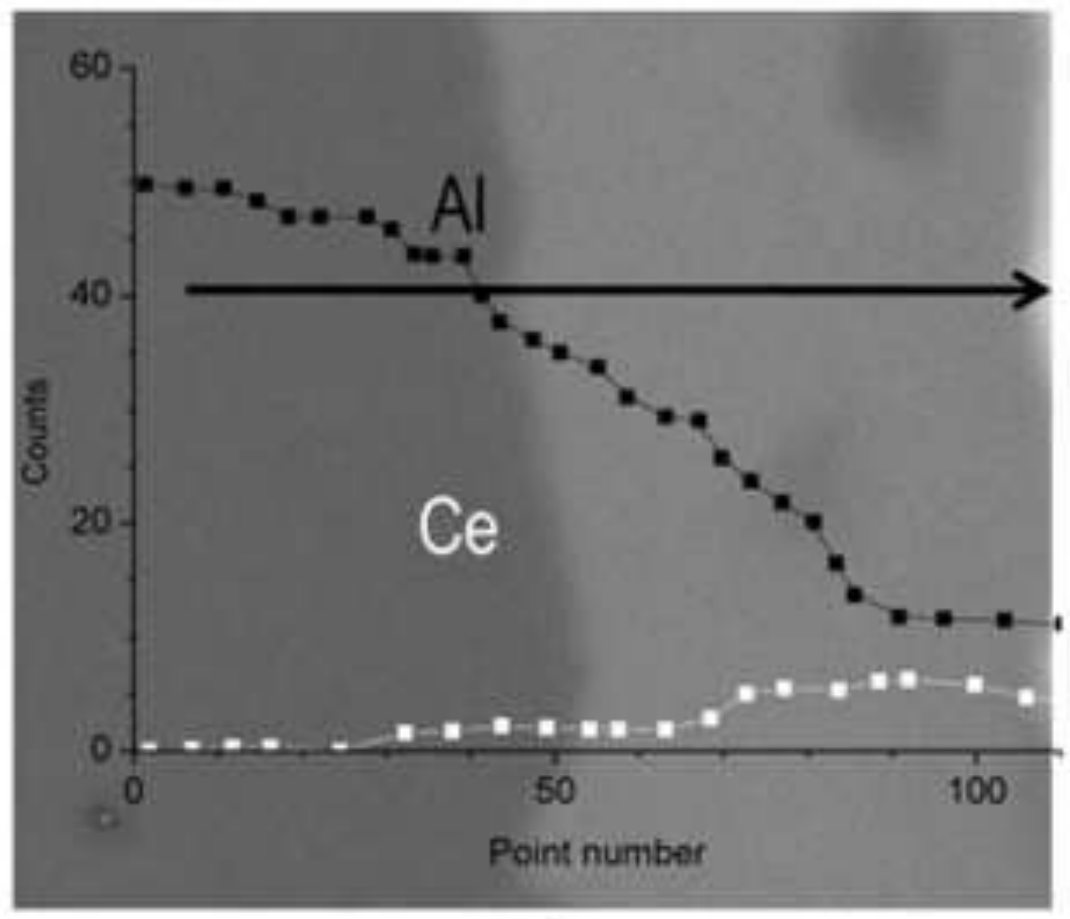

c) 
Click here to download high resolution image
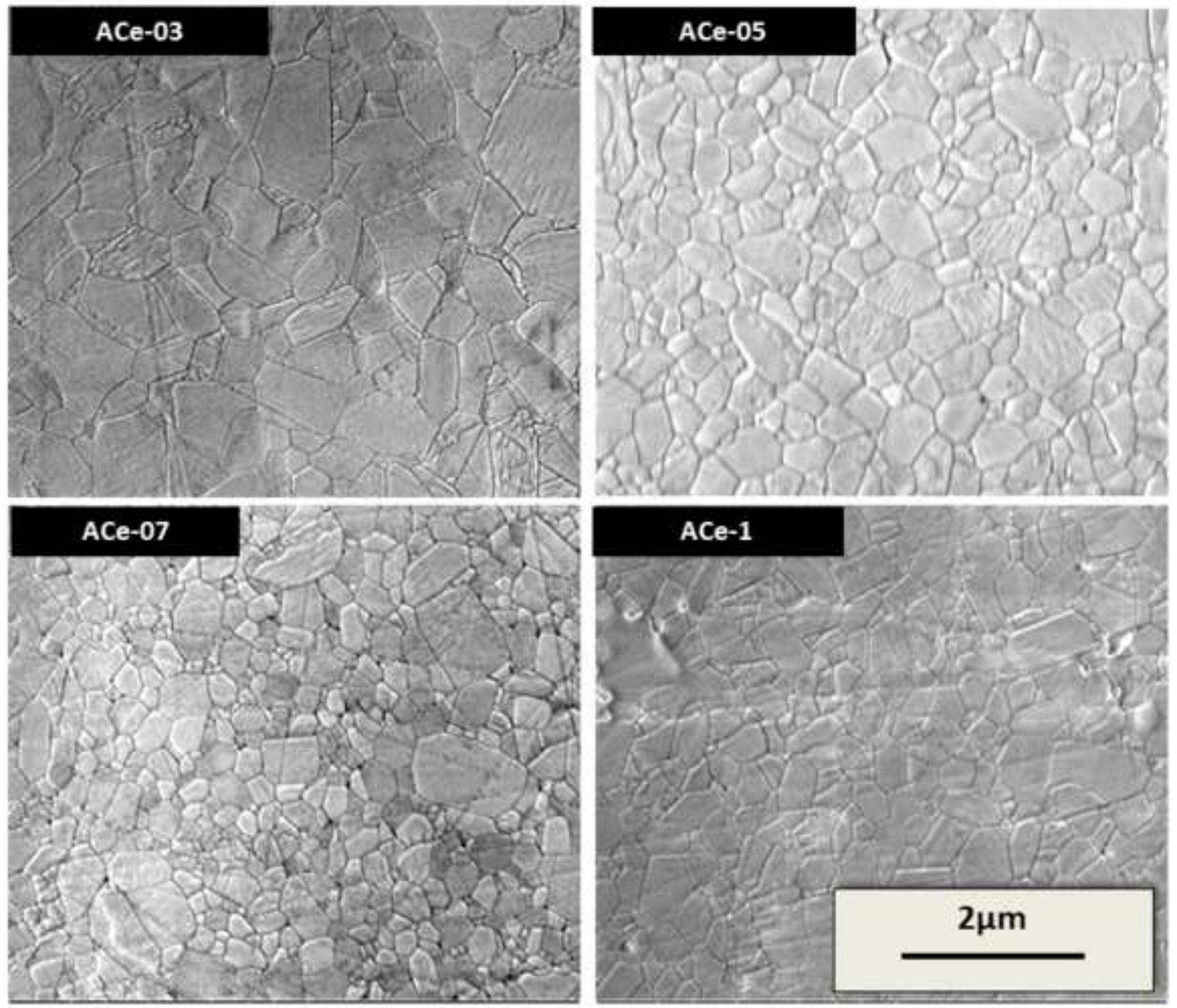
Click here to download high resolution image

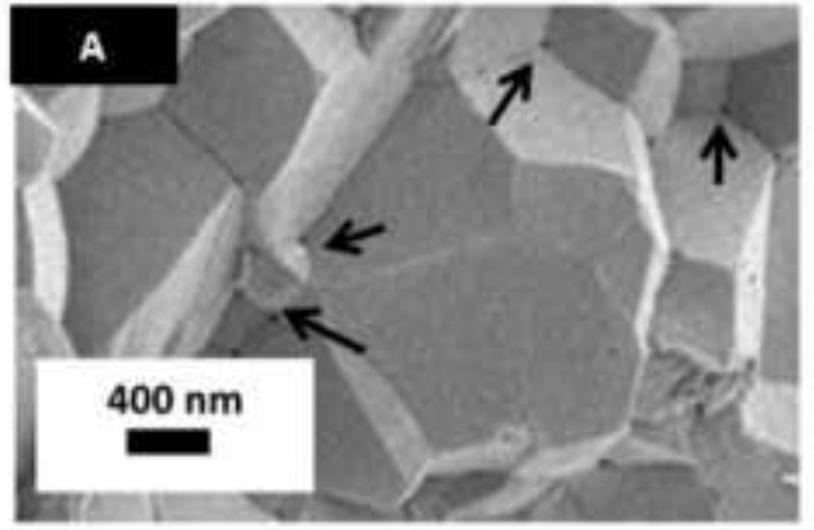

a)

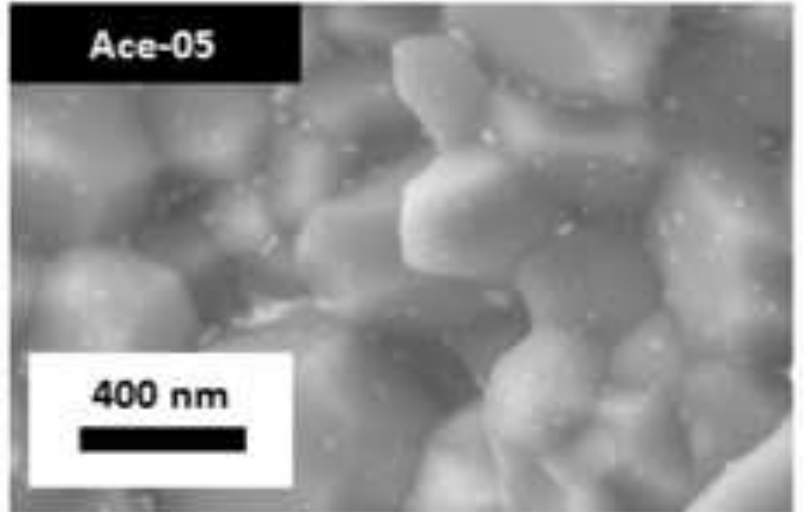

b)

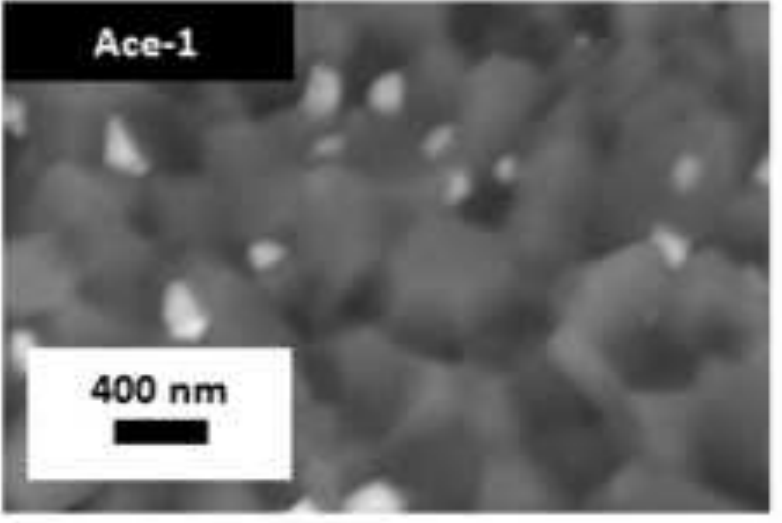

c) 


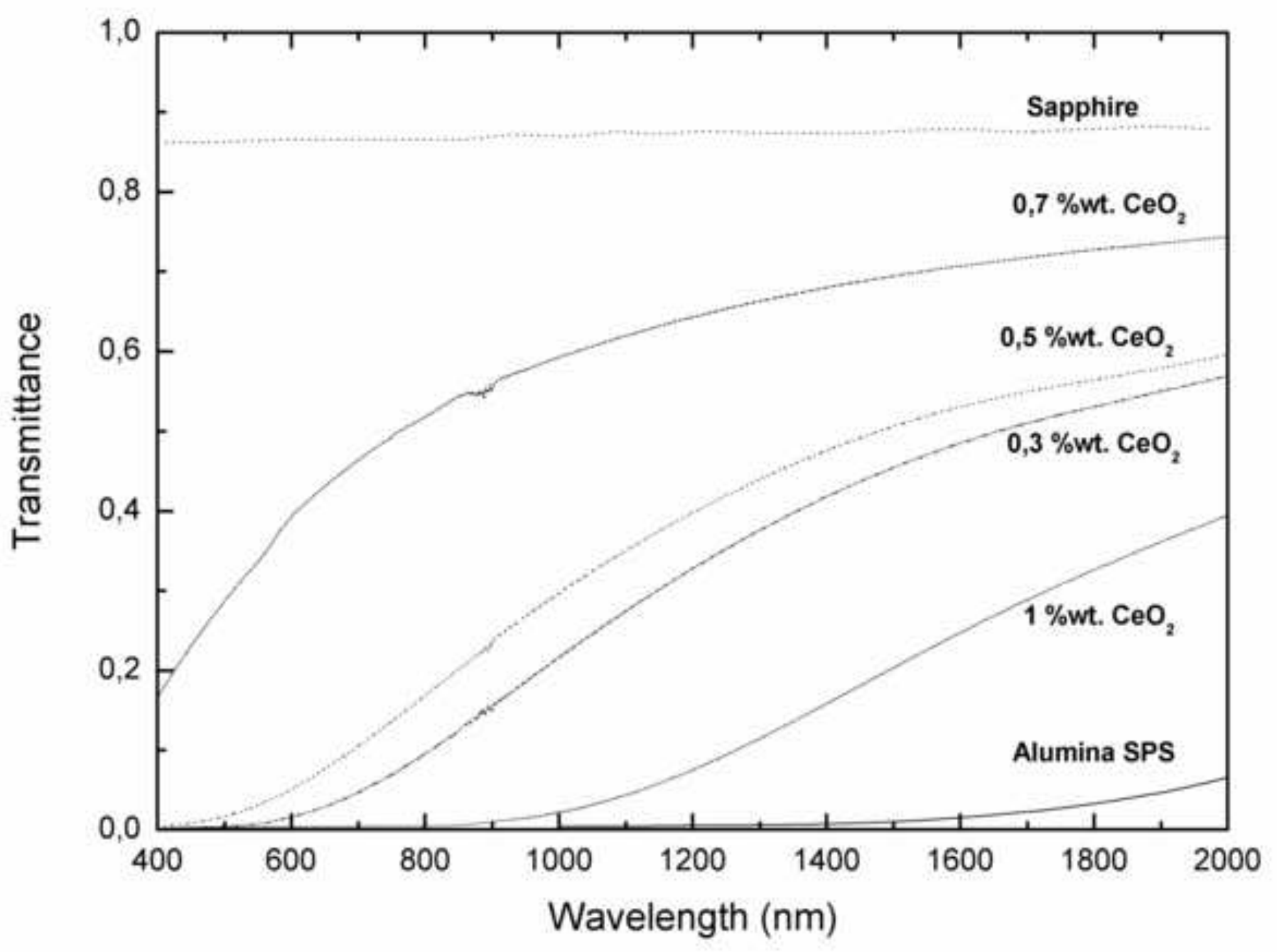




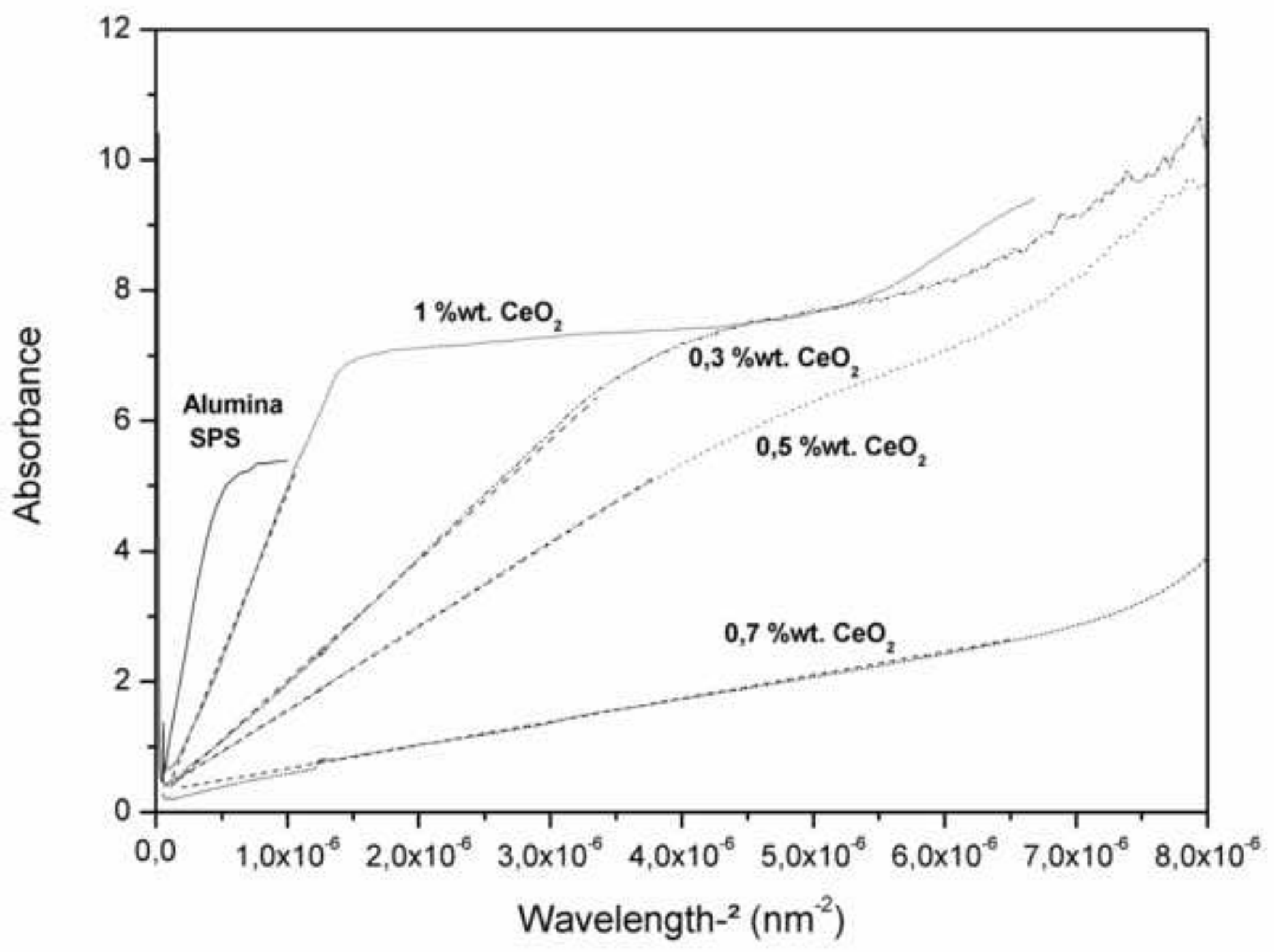




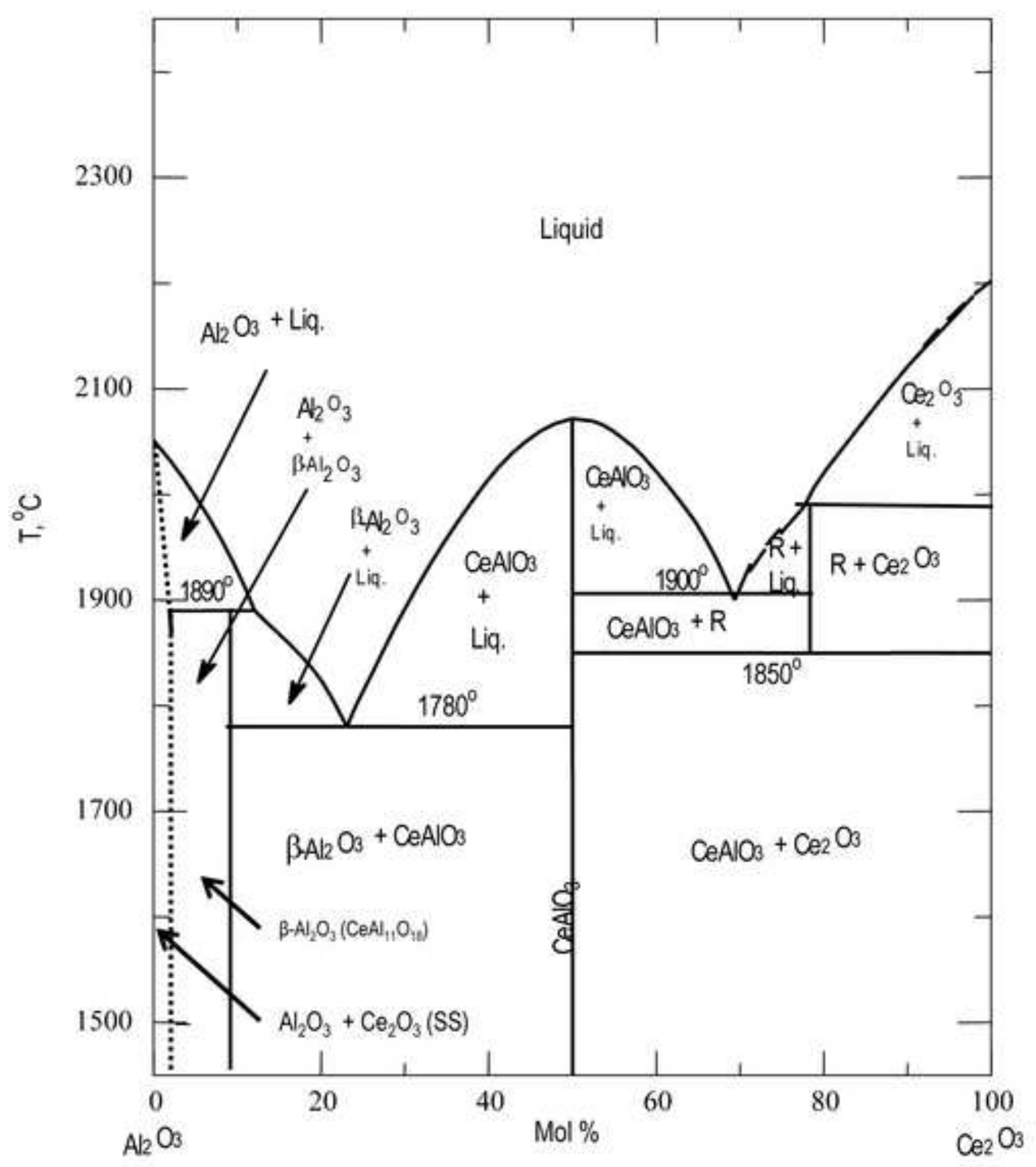




\begin{tabular}{|ccccc|}
\hline Sample & $\begin{array}{c}\text { wt\%. } \\
\mathbf{C e O} \mathbf{O}_{\mathbf{2}}\end{array}$ & $\begin{array}{c}\text { Alumina grain } \\
\text { size } \\
\text { (microns) }\end{array}$ & $\begin{array}{c}\text { Maximum calculated grain } \\
\text { diameter } \mathbf{A l}_{\mathbf{2}} \mathbf{O}_{\mathbf{3}} \\
\text { (microns) }\end{array}$ & $\begin{array}{c}\text { Maximum measured grain } \\
\text { diameter } \mathbf{A l}_{\mathbf{2}} \mathbf{O}_{\mathbf{3}} \\
\text { (microns) }\end{array}$ \\
$\mathrm{A}$ & 0 & $2,8 \pm 0.1$ & 6 & 5.7 \\
Ace-03 & 0.3 & $0.72 \pm 0.11$ & 2.2 & 2 \\
Ace-05 & 0.5 & $0.49 \pm 0.03$ & 1.3 & 1.3 \\
Ace-07 & 0.7 & $0.38 \pm 0.03$ & 0.6 & 0.85 \\
Ace-1 & 1 & $0.47 \pm 0.02$ & - & 1.14 \\
\hline
\end{tabular}

